\title{
TINJAUAN SISTEM PENYIMPANAN REKAM MEDIS MENURUT STANDAR AKREDITASI PUSKESMAS DI PUSKESMAS SUKARAMAI TAHUN 2019
}

\author{
Valentina \\ Dosen STIKes Imelda, Jalan Bilal Nomor 52 Medan \\ E-mail: valentinave89@gmail.com
}

\begin{abstract}
ABSTRAK
Sistem penyimpan rekam medis menjadi salah satu penilaian dalam standar akreditasi puskesmas. Sistem penyimpanan berkas rekam medis sangat penting untuk dilakukan dalam institusi pelayanan kesehatan, karena sistem penyimpanan dapat mempermudah berkas rekam medis yang akan disimpan dalam rak penyimpanan, mempercepat ditemukan kembali atau pengambilan berkas rekam medis yang disimpan di rak penyimpanan, mudah pengembaliannya, dan melindungi berkas rekam medis dari bahaya pencurian, bahaya kerusakan fisik, kimiawi, dan biologi. Tujuan penelitian ini untuk mengetahui penyimpanan rekam medis berdasarkan standar akreditasi puskesmas di Puskemas Sukaramai. Jenis penelitian menggunakan metode penelitian kualitatif dengan pendekatan fenomologi. Penelitian dilakukan pada bulan Oktober 2018-Januari 2019. Populasi adalah seluruh petugas rekam medis di Puskesmas Sukaramai. Sampel penelitian berjumlah 6 orang yang diambil secara purposive sampling. Instrumen penelitian yaitu pedoman wawancara dan direkam menggunakan alat perekam audio serta lembar check list untuk observasi. Hasil penelitian diketahui bahwa sistem penyimpanan yang dilakukan di Puskesmas Sukaramai menggunakan family folder, sistem penjajarannya menggunakan Straight Numerical Filing $(S N F)$, pengambilan berkas rekam medis masih sering dilakukan oleh petugas lain yang bukan petugas rekam medis, tidak adanya penggunaan tracer, dan belum menggunakan buku ekspedisi peminjaman, serta sistem pengembalian berkas rekam medis tidak dipulangakan pada akhir jam kerja. Disarankan bagi pihak puskesmas untuk menambah jumlah petugas rekam medis sesuai kualifikasi pendidikan formal serta pembagian tugas tanggung jawab yang jelas, memberikan pelatihan pada petugas filling, pengambilan rekam medis hanya dilakukan oleh petugas filling, membuat tracer dan buku ekspedisi peminjaman rekam medis serta menentukan waktu pengembalian berkas rekam medis.
\end{abstract}

Kata Kunci : : Manajemen, Rekam Medis, Akreditasi, Puskesmas .

\section{PENDAHULUAN}

Puskesmas adalah fasilitas pelayanan kesehatan yang menyelenggarakan upaya kesehatan masyarakat dan upaya kesehatan perseorangan tingkat pertama, dengan lebih mengutamakan upaya promotif dan preventif untuk mencapai derajat kesehatan masyarakat yang setingi-tingginya di wilayah kerjanya (Permenkes RI, 2015). Dalam menyelenggarakan fungsinya, puskesmas harus melaksanakan rekam medis (Permenkes RI, 2014).

Rekam medis adalah berkas berisi catatan dan dokumen tentang identitas pasien, pemeriksaan, pengobatan, tindakan, dan pelayanan lain kepada pasien pada sarana pelayanan kesehatan (Hatta, 2014).

Pengelolahan rekam medis di puskesmas terdiri dari cara pemberian nomor rekam kesehatan keluarga, assembling, analisa kelengkapan, penyimpanan dan distribusi (Ulfa, 2015).

Sistem penyimpanan berkas rekam medis sangat penting untuk dilakukan dalam institusi pelayanan kesehatan, karena sistem penyimpanan dapat mempermudah berkas rekam medis yang akan disimpan dalam rak penyimpanan, mempercepat ditemukan kembali atau pengambilan berkas rekam 
medis yang disimpan di rakpenyimpanan, mudah pengembaliannya, dan melindungi berkas rekam medis dari bahaya pencurian, bahaya kerusakan fisik, kimiawi, dan biologi (Hatta, 2014). Sistem penyimpan rekam medis menjadi salah satu penilaian dalam standar akreditasi puskesmas (Menkes RI, 2015).

Akreditasi Puskesmas adalah pengakuan tehadap puskesmas yang dinilai telah memenuhi standar pelayanan puskesmas untuk meningkatkan mutu pelayanan puskesmas yang berkesinambungan. Puskesmas wajib mengadakan penilaian akreditasi setiap tiga tahun sekali. Kriteria yang memuat penilaian tentang penyimpanan rekam medis yaitu kriteria 8.4.3 yaitu adanya sistem yang memandu penyimpanan dan pemrosesan rekam medis (Permenkes RI, 2015). Akreditasi berdampak pada peningkatan kualitas mutu pelanyanan. Dengan adanya akreditasi maka mutu pelayanan puskesmas akan jauh lebih baik.

Hasil survei awal diketahui bahwa Puskesmas Sukaramai sudah terakreditasi dengan status Pelayanan Kesehatan Dasar pada Desember 2017. Dalam pelaksanaan penyimpan masih ditemukan kekeliruan penyimpanan (misfile). Oleh karena itu perlu adanya evaluasi persiapan akreditasi agar puskesmas dapat meningkatkan mutu pelayanan rekam medis dan lebih siap menghadapi penilaian akreditasi selanjutnya.

\section{Perumusan Masalah}

Bagaimana sistem penyimpanan rekam medis menurut standar akreditasi puskesmas di Puskesmas Sukaramai?

\section{Tujuan Penelitian}

Tujuan penelitian adalah untuk mengetahui bagaimana pelaksanaan sistem penyimpanan rekam medis rekam medis menurut standar akreditasi puskesmas di Puskesmas Sukaramai.

\section{Manfaat Penelitian}

1. Bagi Puskesmas

Sebagai bahan masukan dan saran bagi pihak puskesmas sebagai bahan evaluasi tentang sistem penyimpanan rekam medis berdasarkan standar akreditasi puskesmas.

2. Bagi Intitusi Pendidikan

Penelitian ini diharapkan dapat digunakan sebagai bahan referensi dan pengembangan ilmu pengetahuan dalam bidang rekam medis.

\section{METODE}

\section{Jenis Penelitian}

Jenis penelitan ini dilakukan dengan menggunakan metode penelitian kualitatif dengan pendekatan fenomologi. Pendekatan fenomologi merupakan suatu metode penelitian yang kritis dan menggali fenomena yang ada secara sistematis (Suryono, 2013).

\section{Waktu Penelitian}

Waktu penelitian dilakukan pada bulan Oktober 2018 sampai Januari 2019

\section{Tempat Penelitian}

Tempat penelitian ini dilakukan di Puskesmas Sukaramai Medan berlokasi di Jl. Arif Rahman Hakim No.28, Gg. Kantil, Medan Area, Kota Medan, Sumatera Utara.

\section{Populasi}

Populasi adalah seluruh petugas rekam medis di Puskesmas Sukaramai.

\section{Sampel dan Teknik Sampling}

Sampel dalam penelitian ini berjumlah 6 orang yang diambil secara purposive sampling, artinya sampling yang dilakukan dengan pertimbangan tertentu (Isgiyanto, 2009). Adapun kriteria inklusinya adalah bekerja di bagian rekam medis puskesmas minimal 2 tahun

\section{Instrumen Penelitian}

Instrumen penelitian yang digunakan dalam penelitian ini yaitu pedoman wawancara dan direkam menggunakan alat perekam audio serta lembar check list untuk observasi.

\section{Cara Pengumpulan Data}

Pengumpulan data dilakukan dengan wawancara dan observasi 


\section{Analisis Data}

Dalam penelitian ini analisa data dilakukan secara deskriptif melalui reduksi data, penyajian dan penarikan kesimpulan, sehingga diperoleh gambaran yang jelas tentang sistem penyimpanan berdasarkan standar akreditasi puskesmas di Puskesmas Sukaramai.

\section{HASIL}

\section{Karakteristik Informan}

Tenaga kesehatan yang bertugas di bagian rekam medis seluruhnya bukan berlatar belakang pendidikan formal rekam medis. Tabel 1 menunjukkan bahwa 3 orang berpendidikan D-III Kebidanan, 1 orang berpendidikan D-III Keperawatan, 1 orang berpendidikan D-IV Kebidanan dan 1 orang berpendidikan SMA.

Tabel 1. Karakteristik Informan

\begin{tabular}{llll}
\hline $\begin{array}{c}\text { Petugas } \\
\text { Koding }\end{array}$ & $\begin{array}{c}\text { Jenis } \\
\text { Kelamin }\end{array}$ & Usia & \multicolumn{1}{c}{ Pendidikan } \\
\hline Informan 1 & Perempuan 29 tahun & D-IV Kebidanan \\
\hline Informan 2 & Perempuan 28 tahun & D-III Kebidanan \\
\hline Informan 3 & Perempuan 32 tahun & D-III \\
& & Keperawatan \\
\hline Informan 4 Perempuan 32 tahun & D-III Kebidanan \\
\hline Informan 5 Perempuan 30 tahun & D-III Kebidanan \\
\hline Informan 6 Laki-laki & 53 tahun & SMA \\
\hline
\end{tabular}

\section{Sistem Penyimpanan Rekam Medis}

Berdasarkan hasil observasi yang peneliti lakukan, berkas rekam medis di Puskesmas Sukaramai dikelola secara sentralisasi mengunakan sistem penyimpanan Stright Numerical Filing (SNF) dengan sistem penomoran family folder berdasarkan wilayah.

Tabel 2. Hasil Observasi Penyimpanan Rekam Medis

\begin{tabular}{lll}
\hline No & Pengamatan & \multicolumn{1}{c}{ Keterangan } \\
\hline 1 & Penomoran & Menggunakan sistem \\
& & penomoran family \\
& & folder yaitu satu berkas \\
& rekam medis digunakan \\
& & oleh satu keluarga \\
& & tetapi belum terdapat \\
& & tambahan kode khusus \\
& & untuk ayah, ibu, dan \\
& & anak. \\
\hline 2 & Penjajaran & Masih menggunakan \\
\hline
\end{tabular}

\begin{tabular}{|c|c|c|}
\hline & & $\begin{array}{l}\text { sistem penyimpanan } \\
\text { Stright Numerical } \\
\text { Filing (SNF) sehingga } \\
\text { sering terjadi tertukar } \\
\text { tempat pada urutan } \\
\text { penomoran. }\end{array}$ \\
\hline 3 & $\begin{array}{l}\text { Sistem } \\
\text { penyimpanan }\end{array}$ & $\begin{array}{l}\text { Sistem penyimpanan } \\
\text { dilakukan secara } \\
\text { sentralisasi, yaitu } \\
\text { berkas rekam medis } \\
\text { rawat jalan dan pasien } \\
\text { IGD disimpan dalam } \\
\text { satu ruangan. }\end{array}$ \\
\hline
\end{tabular}

Sistem Pengambilan Berkas Rekam Medis

Berdasarkan hasil observasi menunjukkan bahwa pengambilan berkas rekam medis tidak hanya dilakukan oleh petugas rekam medis/petugas filing. Perawat dari poli sering mencari dan mengambil sendiri berkas rekam medis pasien yang diperlukan.

Tabel 3. Hasil Observasi Pengambilan Berkas Rekam Medis

\begin{tabular}{lll}
\hline No & Pengamatan & \multicolumn{1}{c}{ Keterangan } \\
\hline 1 & Pengambilan & Perawat poli sering \\
& berkas rekam & sekali mengambil \\
& medis juga & sendiri berkas rekam \\
& dilakukan & medis yang dibutuhkan \\
& selain petugas & \\
\hline
\end{tabular}

Berdasarkan hasil wawancara terkait pengambilan berkas rekam medis diperoleh informasi yaitu:

"Kadang-kadang kalau banyak pasien, rekam medisnya lama sampai, perawatnya ambil sendiri kesini" (Informan 2).

"Yang ngambil berkas rekam medis petugas pendaftaran sama petugas filling. Tapi ada juga perawat yang mencari sendiri jika berkasnya belum sampai ke poli yang dituju" (Informan 4).

\section{Penggunaan Tracer dan Buku Ekspedisi}

Proses pengambiloan berkas rekam medis dimulai dari petugas pendaftaran memberikan/menunjukan KIB (Kartu Identitas Berobat) kepada petugas pendaftaran. Kemudian petugas pendaftaran memberikan nomor rekam medis yang mau dicari oleh petugas filing pada rak penyimpanan setelah ditemukan petugas mengambil berkas tersebut tanpa mengganti 
dengan treacer sebagai alat bantu pengganti berkas rekam medis yang dipinjam dan petugas juga tidak mencatat buku ekspedisi peminjaman berkas rekam medis.

Tabel 4. Tabel Observasi Penggunaan Tracer dan Buku Ekspedisi

\begin{tabular}{lll}
\hline No & Pengamatan & \multicolumn{1}{c}{ Keterangan } \\
\hline 1 & Tracer & Tidak terdapat tracer \\
\hline 2 & Buku & Memiliki buku ekspedisi \\
& Ekspedisi & tetapi tidak digunakan \\
\hline
\end{tabular}

Berdasarkan hasil wawancara terkait penggunaan tracer dan buku ekspedisi diperoleh informasi yaitu:

"Petugas pendaftaran menerima KIB dari pasien lalu melihat nomor rekam medis yang sudah tercantum di sana dan petugas pendaftaran menyuruh petugas filling mengambil berkas rekam medis dari rak penyimpanan, setelah ditemukannya berkas rekam medis tersebut petugas filling langsung memberikannya ke petugas pendaftaran tanpa pemakaian treacer dan tidak menuliskan pada buku ekspedisi" (Informan 3).

"Buku ekspedisi ada, tapi jarang dipakai. Kalau tracer, kami nggak tahu apa itu tracer?" (Informan 5).

\section{Sistem Pengembalian Berkas Rekam Medis}

Hasil observasi dapatkan bahwa petugas filling mengurutkan berkas rekam medis yang telah dikembalikan sesuai nomor rekam medisnya, tetapi pengembalian berkas rekam medis ke dalam rak tidak dilakukan diakhir jam kerja melainkan keesokan harinya.

Tabel 5. Hasil Observasi Pengembalian Berkas Rekam Medis

\begin{tabular}{lll}
\hline No & Pengamatan & \multicolumn{1}{c}{ Keterangan } \\
\hline 1 & Pengembalian & Jika poli \\
& berkas rekam & mengembalikan \\
& medis diakhir & berkas rekam \\
& jam kerja & medisnya keesokan \\
& & harinya maka berkas \\
& & rekam medisnya di \\
& & susun pada keesokan \\
& & hainya \\
\hline
\end{tabular}

Berdasarkan hasil wawancara terkait pengembalian berkas rekam medis diperoleh informasi yaitu:
"Berkas rekam medis dikembalikan sehabis pulang jam bekerja, tetapi jika ada poli yang belum mengembalikan berkas rekam medis kepada petugas filling maka akan di kembalikan pada besok paginya" (Informan 1).

"Rekam medis yang dikembalikan hari ini disusun dulu lalu dimasukan rak, tapi kadang-kadang baru besok dikembalikan dan dimasukan rak" (Informan 6).

\section{PEMBAHASAN}

\section{Sistem Penyimpanan}

Berdasarkan hasil observasi dan wawancara yang peneliti dapatkan dari informan menyatakan bahwa penyimpanan yang dilakukan di Puskesmas Sukaramai menggunakan family folder, tetapi belum terdapat tambahan kode khusus untuk ayah, ibu, dan anak. Sedangkan sistem penjajarannya menggunakan Stright Numerical Filing (SNF).

Hal ini tidak sesuai teori (Budi, 2011), bahwa jenis sistem penjajaran yang sesuai dengan family folder adalah seistem penjajaran Terminal Digit Filing (TDF) yang dikelolah secara sentralisasi.

Adapun akibat yang terjadi jika tidak menggunakan Terminal Digit Filing (TDF) adalah terjadinya pertukaran nomor urut tempat berkas rekam medis pada rak penyimpanan.

\section{Pengambilan Berkas Rekam Medis}

Berdasarkan hasil wawancara dapatkan bahwa pengambilan berkas rekam medis dilakukan oleh petugas filling dengan latar belakang pendidikan bukan rekam medis. Hasil penelitian menunjukkan bahwa petugas rekam medis memiliki tugas lain di puskesmas selain sebagai petugas filling, yaitu menjadi petugas layanan kebidanan dan keperawatan.

Hal ini terjadi karena puskesmas hanya memiliki sedikit petugas rekam medis, sehingga satu pegawai harus memiliki tugas tambahan. Adanya pekerjaan tambahan membuat petugas kelelahan dan tidak fokus dengan pekerjaannya sehingga kinerjanya menurun. Pembagian tugas yang jelas dan uraian tugas masing-masing staf pelaksana 
kegiatan-kegiatan atau program sangat penting agar masing-masing orang bertanggung jawab atas setiap tugas yang dikerjakannya (Isminar, 2015).

Pada proses pengambilan rekam medis, perawat yang ada di setiap poli terkadang mengambil berkas rekam medis sendiri dengan alasan pasien sudah lama menunggu. Hal ini dapat mengakibatkan misfile karena setiap orang bisa bebas keluar masuk ruangan dan mengambil berkas rekam medis. Selain itu pengambilan rekam medis yang dilakukan oleh petugas lain petugas filling mengira berkas rekam meidis tersebut tidak ada sehingga mereka membuat berkas baru yang dapat mengakibatkan duplikasi pada sistem penyimpanan.

Hal ini tidak sesuai dengan Permenkes No. 55 tahun 2013, yang menyatakan bahwa yang berhak melakukan pengambilan berkas rekam medis adalah petugas filling. Petugas filling adalah seseorang yang memiliki kompetensi perekam medis yang diharapkan benar-benar mengetahui seluk beluk tentang rekam medis secara luas dan mendalam.Karena salah satu kompetensi rekam medis adalah mampu mengelolah rekam medis dan informasi kesehatan untuk memenuhi layanan medis, administrasi dan kebutuhan informasi kesehatan.

\section{Penggunaan Tracer dan Buku Ekspedisi}

Berdasarkan hasil penelitian diperoleh bahwa tidak terdapat tracer pada saat pengambilan berkas, dan tidak dilakukan pencatatan pada buku ekspedisi saat peminjaman dan pemulangan berkas rekam medis. Petugas filling juga tidak mengetahui bentuk dan kegunaan tracer.

Menurut Budi (2011), tracer digunakan sebagai pengganti berkas rekam medis di rak filling yang dapat digunakan untuk menelusur keberadaan rekam medis.

Hal yang terjadi apabila tidak digunkannya tracer pada sistem penyimpanan adalah misfile karena petugas filling tidak tau berkas rekam medis itu berada di poli mana.

Menurut Rustiyanto dan Rahayu, 2011) langkah-langkah pengambilan berkas rekam medis yaitu:

1. Menerima tracer yang sudah terisi.
2. Mencari nomor rekam medis.

3. Menyelipkan tracer pada dokumen rekam medis yang sudah diambil.

4. Mengambil dokumen rekam medis yang sudah ditemukan.

5. Mencatat rekam medis yang keluar pada buku ekspedisi.

Penelitian Mahendra

membuktikan bahwa penggunaan tracer di UPT 1 Puskesmas Wonosari 1 dapat mengurangi berkas misfile.

\section{Sistem Pengembalian Berkas Rekam Medis}

Berdasarkan hasil penelitian menunjukkan bahwa pengembalian berkas rekam dilakukan setelah jam kerja, tetapi ada poli yang mengembalikan berkas rekam medisnya keesokan harinya pada pagi hari.

Ketentuan yang harus ditaati di tempat penyimpanan bahwa seseorang yang menerima atau meminjam dokumen rekam medis berkewajiban untuk mengembalikan dalam keadaan baik dan tepat waktu. Dalam peminjaman harus dibuat ketentuan berapa lama jangka waktu untuk satu rekam medis diperbolehkan tidak berada di rak penyimpanan (Riyanto, 2012).

Pengembalian yang tidak sesuai dengan ketentuan dapat mengakibatkan misfile pada sistem penyimpanan, dan petugas filling pada keesokan harinya menjadi kewalahan karena harus menyusun berkas yang harus dikembalikan dan juga harus mencari berkas dari pasien yang berobat pada hari itu. Sehingga akan terjadi waktu tunggu pasien yang lama dan penumpakan pasien pada pendaftaran.

\section{KESIMPULAN}

Dari hasil penelitian yang dilakuan oleh peneliti didapatkan kesimpulan sebagai berikut:

1. Sistem penyimpanan yang dilakukan di Puskesmas Sukaramai menggunakan family folder, sistem penjajarannya menggunakan Straight Numerical Filing (SNF).

2. Pengambilan berkas rekam medis masih sering dilakukan oleh petugas lain yang bukan petugas rekam medis. 
3. Tidak adanya penggunaan tracer untuk pengganti sementara pengambilan berkas rekam medis, dan juga belum menggunakan buku ekspedisi untuk peminjaman dan pemulangan berkas rekam medis.

4. Sistem pengembalian berkas rekam medis tidak dipulangakan pada akhir jam kerja.

\section{SARAN}

1. Bagi Puskesmas

a. Menambah jumlah petugas rekam medis sesuai kualifikasi pendidikan formal serta pembagian tugas tanggung jawab yang jelas.

b. Memberikan pelatihan atau pembinaan secara rutin pada petugas filling.

c. Pengambilan rekam medis hanya dilakukan oleh petugas filling agar tidak terjadi kekeliruan pada saat pencarian berkas rekam medis.

d. Membuat tracer yang digunakan pada saat pengambilan berkas rekam medis, dan dilakukan penulisan pada buku ekspedisi peminjaman rekam medis.

e. Sebaiknya diterapkan dengan jelas waktu pengembalian berkas rekam medis kepada petugas filling.

\section{DAFTAR PUSTAKA}

Budi S Citra. (2011). Manajemen Unit Kerja Rekam Medis. Yogyakarta: Quantum Sinergis Media.

Hatta, Gemala R. (2014). Pedoman Manajemen Informasi Kesehatan Disarana Pelayanan Keseshatan.
Jakarta: Universitas Indonesia (UIPress).

Isminar, Hetty. (2015). Manajemen Unit Kerja. Yogyakarta: Deepublish.

Mahendra, A. (2011). Pemanfaatan Tracer di Bagian penyimpanan berkas Rekam medis di UPT Puskesmas Wonosari 1. Tugas Akhir. Yogyakarta: Program Studi Rekam Medis UGM.

Menkes RI. (2004). Standart Akreditasi Puskesmas. Jakarta: Kementerian Kesehatan.

Menkes RI. (2014). Peraturan Menteri Kesehatan RI No. 75 tahun 2014. Pusat Kesehatan Masyarakat. Jakarta: Menteri Kesehatan Republik Indonesia.

Menkes RI. (2015). Peraturan Menteri Kesehatan RI No.46 tahun 2016. Akreditasi Puskesmas, Klinik Pratama, Tempat Praktik Mandiri Dokter, Dan Tempat Praktik Mandiri Dokter Gigi. Jakarta: Menteri Kesehatan Republik Indonesia.

Rustiyanto E, Rahayu W Amba. (2004). Manajemen Filing Dokumen Rekam Medis dan Informasi Kesehatn. Yogyakarta: Poltekkes Permata Indonesia.

Riyanto, Budi. (2012). Tinjauan Pelaksanaan Penyimpanan Dan Pengambialan Dokumen Rekam Medis di Bidang Filing RSUD Kabupaten Karanganyar Tahun 2012. Rekam Medis. Vol.6. No.2. Oktober 2012: 5058.

Ulfa, H Maria. (2015). Analisis Pelaksanaan Pengelolaan Rekam Medis di Puskesmas Harapan Raya Kota Pekan Baru. Manajemen Informasi Kesehatan Indonesia. Vol.3. No.2. Oktober 2015: 39-40. 